ARTICLE

https://doi.org/10.1057/s41599-020-0388-5

\title{
Setting the agenda for social science research on the human microbiome
}

\author{
Beth Greenhough (10) et al. ${ }^{\#}$
}

\begin{abstract}
The human microbiome is an important emergent area of cross, multi and transdisciplinary study. The complexity of this topic leads to conflicting narratives and regulatory challenges. It raises questions about the benefits of its commercialisation and drives debates about alternative models for engaging with its publics, patients and other potential beneficiaries. The social sciences and the humanities have begun to explore the microbiome as an object of empirical study and as an opportunity for theoretical innovation. They can play an important role in facilitating the development of research that is socially relevant, that incorporates cultural norms and expectations around microbes and that investigates how social and biological lives intersect. This is a propitious moment to establish lines of collaboration in the study of the microbiome that incorporate the concerns and capabilities of the social sciences and the humanities together with those of the natural sciences and relevant stakeholders outside academia. This paper presents an agenda for the engagement of the social sciences with microbiome research and its implications for public policy and social change. Our methods were informed by existing multidisciplinary science-policy agendasetting exercises. We recruited 36 academics and stakeholders and asked them to produce a list of important questions about the microbiome that were in need of further social science research. We refined this initial list into an agenda of 32 questions and organised them into eight themes that both complement and extend existing research trajectories. This agenda was further developed through a structured workshop where 21 of our participants refined the agenda and reflected on the challenges and the limitations of the exercise itself. The agenda identifies the need for research that addresses the implications of the human microbiome for human health, public health, public and private sector research and notions of self and identity. It also suggests new lines of research sensitive to the complexity and heterogeneity of human-microbiome relations, and how these intersect with questions of environmental governance, social and spatial inequality and public engagement with science.
\end{abstract}

\footnotetext{
\#A full list of authors and their affiliations appears at the end of the paper.
} 


\section{Introduction}

he term human microbiome describes the collective genome of the microorganisms that live on and inside the human organism (Hooper and Gordon, 2001). It is often taken to stand more broadly for the collective of microbes of a given ecosystem, although this would be more correctly termed microbiota. (In this paper we use the term human microbiome, but remain aware that in popular discourse there may be some slippage between the two terms.) While research on the human microbiome is still very much in its infancy, it promises to change how we think about health, disease and human-environment relations (Lederberg, 2004), although experts caution against confusing the hope with the hype (Neiderhuber, 2015). Innovations in research methods, and in particular the development of metagenomics (National Academies of Sciences, Engineering and Medicine, 2007), have significantly expanded the ability to study microorganisms, by 'allowing a microbial community's composition to be defined by DNA sequencing without having to culture its members' (Benezra et al., 2012, p. 1). This has facilitated an expansion of research agendas, moving from the isolation and eradication of singular pathogens towards the mapping of collective microbial life in all of its complexity, diversity and functionality. Central to this work, from a human health perspective, has been the increasing prominence given to how humans evolve with and are dependent on many of the bacteria and viruses which inhabit human skin, organs, mucous membranes and intestinal tract (Gilbert et al., 2018).

Consequently, while pathogenic microbes remain a key concern for both scientific researchers and policy-makers in the UK and elsewhere, especially in the wake of the rapid growth of antimicrobial resistance (AMR) (O'Neill, 2014), there are also a growing number of initiatives focused on exploring what has been termed the 'new microbial frontier' (Microbiology Society, 2017). The most well-known of these is the Human Microbiome Project (HMP) launched by the US National Institutes of Health (NIH) in 2007 to map the genome of the microbial communities which inhabit the human body and explore their role in human health and disease (Human Microbiome Project Consortium, 2012; The Integrative Human Microbiome Project, 2019). Similar initiatives are also underway in Canada, France, Japan, Singapore and Australia, while the European Commission has supported a plethora of research initiatives, such as the Metagenomics of the Human Intestinal Tract (MetaHIT) study, focused on mapping gut microbiota and their relations to health conditions (Rhodes et al., 2013). In the commercial domain we are witnessing a proliferation of companies that seek to capitalise on emerging knowledge of the microbiome to develop commercial applications, often by hybridising traditional corporate strategies and novel 'citizen science' platforms. UBiome (n.d.), for example, combines the provision of a commercial personalised sequencing service with the opportunity to contribute as 'citizen scientists' to their microbiome database, although this raises questions about the way in which such projects can be used to effectively reinforce biological conceptions of race (Roberts, 2012) and the inclusiveness of biomedical citizen science more broadly (Fiske et al., 2019). We have also witnessed a rapid growth in the number of products that see the human microbiome as a new way of defining a target market, including food and probiotic supplements designed to influence everything from gastrointestinal health to mood, cosmetics utilising skin microbiome knowledge, and 'microbiota friendly' household cleaning and pest control products.

In sum, scientific knowledge and commercial interest in the close relationship between humans and their microbiota is growing exponentially. This growth is echoed in popular culture in the form of a "microbiomania" (Eisen, n.d.; Helmreich, 2015) within the scientific press, in which microbes are described in highly evocative terms as novel (or newly appreciated) actors capable of both endangering and sustaining human existence (Shnayerson and Plotkin, 2002; Velasquez-Manoff, 2012; Yong, 2016). This knowledge is not completely new. Probiotic traditions have existed for millennia and many of the understandings of the body, the environment, health and disease associated with some of these traditions present close correlates with currently developing views (Giraldo Herrera, 2018; McFarland, 2015). Furthermore, elements of this new science had already been foregrounded by early figures of microbiology such as Metchnikoff (Metchnikoff, 2016, 1903; Sangodeyi, 2014). However, new scientific knowledge about the role of microbes in fostering human health and wellbeing is leading to new configurations of value and expectation. These are evident in concerns about the promissory nature of microbiome hype, a concern common in emerging life science areas (Neiderhuber, 2015), conflicting narratives about the validity of the hygiene hypothesis (Blaser, 2014; Bloomfield, 2016), innovations in the form of patient engagement in microbiota-related interventions - such as Do-It-Yourself (DIY) or hacking approaches to Faecal Microbiota Transplantation (FMT) (Wolf-Meyer, 2017) and helminth therapy (Lorimer, 2016) - and new approaches to regulation and commercialisation (Chuong et al., 2017; Hawkins and O’Doherty, 2011; Rhodes et al., 2013).

In the context of emerging technoscientific innovation and associated policy agendas, there is increasingly an acknowledgment of the need for social-scientific scholarship to contribute to the framing and interpretation of research (Stilgoe et al., 2013; "Time for the social sciences," 2015). This is reflected in calls for social and biological scientists to collaborate in the production of a better understanding of the intersection between human and microbial worlds (Benezra et al., 2012). As Stirling (2014) notes, however, all too often the social sciences are brought in only at the end of grand multidisciplinary procedures, to inform implementation strategies or communication plans, rather than to help determine policy directions'. Sometimes known as the subordinate-service mode of interdisciplinarity (Barry et al., 2008), this approach has been challenged by recent work in the science and technology studies (STS) which promotes intensely collaborative approaches to interdisciplinary research (Balmer et al., 2016; Brown et al., 2015; Callard and Fitzgerald, n.d.; Clinch et al., 2018; Nowotny, 2016). Taking inspiration from these more careful approaches to biosocial collaboration, the purpose of our exercise is not to offer a social science 'response' to existing scientific research agendas, but to ask how social scientists might lead new and emerging interdisciplinary research programmes driven by questions and concerns of interdisciplinary relevance.

Work of this kind has already begun in a range of research projects and theoretical programs exploring one or another form of what Paxson has termed "microbiopolitics" (Bloomfield, 2016; Paxson, 2008). More often than not, the focus in this literature is on one aspect of the microbiome and its implications for a specific interest group: for example, the intersection between the human microbiome and biobanking within an Ethical, Legal and Social Issues (ELSI) framework (Chuong et al., 2017; Hawkins and O'Doherty, 2011); public engagement with the microbiome in the spirit of Responsible Research and Innovation (RRI) (Shamarina et al., 2017); microbiome geographies and anthropologies (Krzywoszynska, 2019; Lorimer, 2016, 2017; Maroney, 2017; Nading, 2016); microbiomes of the built environment (National Academies of Sciences, 2017); and the relationship between microbiome and antimicrobials (Landecker, 2016). An exception to this piecemeal approach is the edited volume on The Human Microbiome: Ethical, Legal and Social Concerns (Rhodes 
et al., 2013), which emerged from a working group of 27 health professionals, scientists and humanities and social science scholars established through the HMP. This group highlighted a number of areas of concern, including the impact of the human microbiome on conceptions of identity, questions of ownership and property rights, issues of privacy, research ethics, biobanking and questions of public health and research on populations, as well as making a series of related policy recommendations. (See also Benezra $(2016,2018)$ on the need to develop collaborations between social scientists and human microbial ecologists).

In contrast to The Human Microbiome: Ethical, Legal and Social Concerns, which focused on integrating disciplinary perspectives from within the academy, our exercise follows in the vein of other recent collaborative agenda-setting exercises that have sought to open up the formulation of the agenda in question to a wider range of stakeholders (Davies et al., 2016). We shared this ambition with a recent report of the UK Microbiology Society (Microbiology Society, 2017), 'Unlocking the microbiome,' which consulted 160 participants from across academia, research funding bodies, regulators and users of microbiome research. Other notable initiatives to include the social sciences in the setting of microbiome-related research agendas in the UK context include the significant growth in grant calls around AMR (ESRC (Economic and Social Research Council) 2014; Tackling AntiMicrobial Resistance (AMR)-Arts and Humanities Research Council, n.d.) and more broadly, the advent of the cross-council AMR research initiative that, acknowledging the need for interdisciplinary approaches to AMR, brought all seven research councils together for the first time to provide joint funding for AMR research. This AMR focus is understandable given its status as a global health priority posing an immediate threat to human health; furthermore, the AMR focus may also serve to foster the growing interest in the microbiome.

In our agenda-setting exercise we took two strategic decisions: to focus on the human microbiome (while recognising that the human microbiome is part of and interacts with the global microbiome) and to leave open the question of whether, how and why this human microbiome might be relevant to human health and wellbeing, thus allowing for diverse 'matters of concern' (Latour, 2004) to emerge in the exercise itself. This decision was inspired by recent work in the social sciences and environmental humanities (Paxson and Helmreich, 2014) that highlights the broad and diverse range of challenges, opportunities and questions raised by the current microbial turn.

Methodologically, we took inspiration from a series of recent agenda-setting exercises. Some of these have focused on setting agendas for future scientific work exploring ecological and global biological diversity issues (Sutherland et al., 2009, 2006). Later experiments have focused on complex and challenging sciencepolicy relationships (Davies et al., 2016; Parker et al., 2014; Sutherland et al., 2012, 2011) and on the relations between science and business (Armsworth et al., 2010). While some of the questions discussed below specifically address policy pathways and choices, our exercise was primarily concerned with setting an agenda for social science research, partly to resist framing social science research as orientated towards (and constrained by) policy concerns. As with other similar exercises (Sutherland et al., 2012), this paper therefore both reflects on and acknowledges the complex and contradictory nature of science-policy relations and the limits of evidence-based policy.

Below we provide an overview of the collaborative process through which we sought to devise a shared social-scientific research agenda on the human microbiome. Through this process key questions were identified that could valuably inform future interdisciplinary scholarship on the microbiome, bringing together researchers from the social sciences with those working in the natural sciences and humanities, as well as non-academic stakeholders. A number of key themes emerged, including: (i) the impact of new knowledge about the microbiome on healthcare governance and practice; (ii) the impact of 'microbiomania' (Helmreich, 2015) on human-microbe relations; (iii) the intersection of human microbiome and environmental governance; (iv) microbiome imaginaries and narratives; ( $v$ ) the intersection of microbiome knowledges, identity and citizenship; (vi) the commodification of microbes; (vii) the relationship between the microbiome and its publics and (viii) the relationship between the microbiome and academic research. In the final discussion we reflect on the nature of the priorities and questions emerging from the exercise, the potential role of the social sciences in microbiome research and the usefulness of this kind of exercise for shaping future social science work.

\section{Method}

This collaborative agenda-setting exercise was organised and facilitated by a small team of social scientists who are all members of the Oxford Interdisciplinary Microbiome Project (IMP). The process involved four stages: recruiting participants, generating questions, agreeing priorities and the collective drafting of outcomes. The ultimate objective of the workshop was to produce a refined list of questions to serve as a proposed research agenda for social science work on the human microbiome. In addition, we envisioned that this exercise would provide scope and space for interdisciplinary and transdisciplinary conversations with key stakeholders and interest groups, and a basis for building networks and capacities for future research. Below we describe the four-stage process, modelled on previous exercises (Davies et al., 2016; Sutherland et al., 2012, 2011).

Stage 1: Participant recruitment. Previous agenda-setting exercises, looking at issues such as ecology, biodiversity and laboratory animal research, have differed significantly in scope, with some comprising multiple events in several different countries (Rhodes et al., 2013), and some being more UK focused (Davies et al., 2016). In some cases, groups met only once, while others, such as that led by Rhodes et al. (2013), involved an extended period of collective discussion and elaboration. The scale and scope of our exercise in many ways reflected the emerging, rapidly evolving and as yet not-fully-determined nature of the human microbiome as a research field, as well as more pragmatic constraints in terms of time and resources.

In contrast to previous exercises, such as Davies et al.'s (2016) agenda for research on laboratory animal welfare, there was not an easily defined and delineated range of stakeholders, although the recent reports of the UK Microbiology Society (Microbiology Society, 2017) and the Royal Society for Public Health (Royal Society for Public Health, 2019) offer some sense of emerging key players. The sampling strategy was deliberately purposive (Davies et al., 2016; Sutherland et al., 2011), drawing on expert knowledge to identify a group of stakeholders who can logically be assumed to be representative of the wider population. We began by reviewing current literature in the field and our existing network established through previous work on the social science of the microbiome (Greenhough et al., 2018; Hodgetts et al., 2018; Lorimer et al., 2019) to generate a list of key research fields and interest groups with the objective of achieving representation from each of these in our exercise. Our target fields were as follows: agriculture, art-science, bioethics, built environment, economics, food, history of science, natural environment, medicine, microbiology, patient organisations, public health and social science. We also worked with representatives from a 
number of key UK organisations with strong interest in the microbiome, including the UK Microbiology Society, the Food Standards Agency, the International Scientific Forum on Home Hygiene and the Environment Agency. Following an initial round of recruitment, we were able to then draw on the expertise of our growing participant group to identify any gaps and identify additional relevant expertise. Given resource constraints we focused on the UK, but also included a number of international perspectives from US and Europe allowing points of comparison to be drawn and to offer some insights into the more global applicability of our findings (the influence of such perspectives is reflected below in some of the questions which address, for example, issues of global inequality). A future exercise would ideally expand this to incorporate a wider range of international perspectives.

As Sutherland et al. (2011, p. 244) note, 'it is a serious challenge to obtain comprehensive coverage of all domains'. While we cannot claim our list is fully representative of the broad range of relevant intellectual motivations and pursuits, it is nevertheless diverse enough to serve our basic purpose: broadening the scope and range of the social-scientific work on the human microbiome. Participants were also encouraged to suggest other contacts to be approached and to consult widely within their networks to strengthen and deepen the range of perspectives included within the exercise. Sutherland et al. (2011) recommend an upper limit of 40 participants for this kind of exercise, as this number is the most that can be comfortably accommodated in a plenary discussion, while further breadth can be achieved by wider consultation. In total, our exercise involved 36 participants, with 21 attending the workshop. Collectively, this group held diverse kinds of expertise in agriculture, anthropology, bioethics, built environment, clinical medicine, environmental health, geography, health care, history of medicine, linguistics, medical research, microbiology, NGOs, patient groups, psychology, science journalism and zoology (see author list).

Stage 2: Generating questions. Participants were invited to send us a list of what they thought were the most interesting and important research questions with respect to the human microbiome. While Sutherland et al. (2011, p. 239) orientated their questions towards the formation of 'directly testable research hypotheses', in our exercise the only limitation posed (beyond its focus on the human microbiome) was that the questions should be amenable to social-scientific research. Again, this reflected our commitment to hold open what might emerge as a relevant 'matter of concern', rather than limiting it to questions or issues that might appear 'testable'. In deciding the list of questions, participants were encouraged to consult widely with colleagues and contacts who shared their interest in microbiome matters. Once formulated, participants were asked send their list of questions to the organisers. The organisers were then responsible for collating these submissions into a long list of 120 questions, organised under broad themes. The questions were left largely unaltered, although organisers carried out some minor editing to put the questions into a format suitable for the exercise. (Participants were invited to add comments if they felt the editing misinterpreted their question). This long list of potential research questions was then sent out to participants with instructions for how to 'vote' for the questions they thought were the most interesting or important. Each person was allocated ten votes to indicate which questions they wanted to prioritise. They were also invited to suggest alternative wording for questions. Any question that received one or more votes was put through to the next stage.

Stage 3: Workshop. In the third stage of the process, participants were invited to attend a workshop in Oxford in the summer of
2017. To facilitate discussion, the questions were divided into eight themes and participants into four groups. Each group was then tasked with working on the questions for two themes. Due to a number of late withdrawals on the day each group contained 5-6 participants, with the team trying to ensure a mix of social scientists, natural scientists and other stakeholders. This number is less than the 10-12 people per group recommended by Sutherland et al. (2011) but nonetheless we found the groups diverse enough to generate robust, thoughtful and challenging discussion (see Discussion section). Each group was chaired by a member of the IMP team to assist them in identifying priorities, removing redundancy and rewording questions to eliminate overlap and improve clarity. Workshop discussions were recorded and detailed notes kept. We draw on these notes in the following section to illustrate some of the complexities and debates that shaped the question-refining process.

In the morning session, the groups were tasked with reducing their list of 15 or so questions for each theme down to three priority and three back-up questions. To assist them in the process, chairs were given lists indicating the number of votes each question had received and were encouraged to drop questions that had received few votes and to identify and possibly combine overlapping questions. Once the groups had agreed their priority questions, these were then brought to an afternoon plenary session, where all workshop participants reconvened to combine question lists, remove any remaining redundancy, reword outcomes and discuss results before the final list of 32 priority questions were agreed.

Stage 4: Dissemination. Finally, the Oxford IMP team processed the results from the workshop and produced a first draft of this paper detailing the process and the agenda developed for publication. This draft was circulated to all participants, who were invited to comment on the paper and, in light of their participation in the process, to be co-authors. Following the example of Sutherland et al. (2012), it was not deemed necessary to seek further ethical approval. Their participation is reflected in the list of authors given above.

\section{Results}

As noted by Sutherland et al. (2012) the questions agreed upon through an agenda-setting exercise like this are unavoidably influenced by the participants who contributed to the process. However, we believe that the general themes that emerged through the voting, deliberation and editing process reported here would be likely to surface if this process was replicated with a similarly large and diverse group of participants. In Table 1 we set out the key themes and research questions that developed following reflection, discussion and debate. Questions are grouped into themes, but not ranked.

\section{Discussion}

In this section, we review the themes and questions that emerged from our exercise and place these in the context of the broader discussions from which they arose. The purpose is not only to reflect on the kinds of issues that were identified as priorities for future social science research, but also to understand the complexity involved in deciding which of the many possible issues are the most pressing for social scientists to address.

Discussion of emerging questions and themes. Some of the themes that emerged from the exercise speak clearly to ongoing areas of scientific and policy concern. The questions that emerged around the themes of 'Microbiome and health', 'Microbiome and cleaning/hygiene' and the 'Microbiome and the environment' all 


\section{Table 1 Results from the agenda-setting exercise, organised by theme.}

\section{Theme: Microbiome and health}

1 How are emerging scientific knowledge and public discourses around the microbiome affecting institutional, vernacular, and other stakeholders' healthcare practices?

2 What is the role of the microbiome in shaping risk and health inequalities?

3 Who is currently taking responsibility for shaping the governance of microbiome interventions? Who should be responsible and who decides?

4 How do we move microbiome interventions from bench to bedside (or vice versa in the context of DIY FMT in humans), and what are the impacts on patients and publics?

\section{Theme: Microbiome and lifestyle}

5 What terms do people use to describe their interactions/relationship with microbiota (e.g. clean, hygienic, sanitised, dirty, decontaminated), and what do they understand by these terms?

6 What practices do people engage in when trying to modulate their relationship with microbes?

7 What public health interventions and scientific research aimed at changing interactions between humans and microbes are already taking place?

8 What are the origins of the current public consciousness and anxieties about hygiene and cleanliness?

\section{Theme: Microbiome and environment}

9 How does the environmental microbiome reframe understandings of (One) health and wellbeing?

10 What are the political and ecological drivers of microbial dysbiosis?

11 Who gets to know, diagnose and manage the environmental microbiome?

12 How does the environmental microbiome interact with prevalent forms of microbiopolitics (knowledge and governance reliant on knowledge of microbes) such as hygiene, cooking, agriculture and biosecurity?

13 What are the implications of the microbiome for prevalent approaches to sustainability: welfare, localism, chemicals?

\section{Theme: Conceptualising the microbiome}

14 How do groups of the public conceptualise the microbiome, if they do at all?

15 How is the microbiome visualised and how does this vary in terms of pathogenic and non-pathogenic microbes?

16 How do narratives and discourses about the microbiome circulate?

\section{Theme: Thinking with microbes}

17 How has the microbiome changed the meaning of citizenship?

18 How do ongoing social practices absorb and shape unfolding knowledge of the microbiome?

19 How might scientific findings relating to the role of the microbiome in human health, and even psychological wellbeing, impact on understandings of the individual?

\section{Theme: Valuing and commodifying the microbiome}

20 What kinds of value (e.g. scientific, popular, commercial) are afforded to microbes and microbial communities, and how have these changed over time? How do these different forms of value interact? How does AMR affect the valorisation of the microbiome?

21 What aspects of the microbiome have been commodified (i.e. translated into commercial products)? How far do processes of commodification map onto both popular and scientific understandings of the microbiome and its value?

22 What claims are being used to market microbiome-related products? How far do these relate to evolving scientific understandings of the microbiome?

23 What counts as owning the microbiome? Does the possibility of commodifying the microbiome change received understandings of what can be invested with property rights (e.g. intellectual property)?

\section{Theme: Engaging publics with the microbiome}

24 What are the common understandings and attitudes towards the microbiome amongst different publics?

25 How, by whom, and through what processes is the microbiome represented and consumed (for example as treatments or dietary interventions)? How does this interface with, affirm or challenge other understandings of health, welfare and the environment?

26 What are the publics of the microbiome? For example, those associated with antibiotics, hygiene, food and prebiotics, dysbiosis and FMT.

27 How might the publics of the microbiome best be brought into existence? What social science technologies are available for experience and experiment?

28 How do we engage with both post-Pasteurian and anti-Pasteurian approaches?

Theme: Researching microbes

29 When and how does the microbiome come into being as an object of scientific inquiry? What does it encompass, what does it exclude and why do certain areas (e.g. the gut) gain particular traction while others do not?

30 What evidentiary techniques are central to the emergence of the microbiome as a distinct object of scientific inquiry?

31 What social science tools (conceptual and methodological) can be harnessed to facilitate interdisciplinary investigations of the microbial connections between humans, animals and the environment?

32 What would a transdisciplinary response to contested areas of microbiological science (e.g. the relationship between gut microbiome and chronic disease) look like, and how far could it engage with lay people's beliefs regarding the influence of the microbiome on their own and others' health and wellbeing?

point to the challenge of measuring, governing and regulating microbial resources, applications and impacts through, for example, food safety protocols, the licensing of medical interventions or new biosecurity protocols. While these issues are not in themselves novel, their inclusion in this agenda alongside questions of health inequalities, biohacking, sustainability and anxieties about the hygiene hypothesis makes an important statement about the interdependency and inter-related nature of many of these concerns, and the significance of the human microbiome as a separate and arguably unique orienting point for new kinds of interdisciplinary work.
Discussions of these themes also raise questions of space and geography. The human microbiome, for instance, raises very different concerns in resource-poor, rapidly urbanising megacities in the global south, and in middle-class urban households in the global north (Lorimer, 2017). Equally, we might note how these same social and spatial inequalities are reflected in the human microbiome and the maps we make of it. The human microbiome to which we often refer is one known mainly through research on white Western populations, reflecting what Crane (2011) might call the 'molecular politics' of microbiome knowledge production. Additionally, questions arose concerning the frequency, duration 
and intensity of relations between humans and particular microbes or groups of microbes (Hinchliffe et al., 2013). Such concerns are reflected in the discussion around defining 'safe interactions' which emerged in the context of domestic cleaning. While these concerns focus mostly on the humans involved, at other times participants questioned the impact of human-microbe relations on microbial differentiation: what environmental factors-animals, spaces, habits, lifestyles, migrations, food, agricultures, abiotic forces, chemical exposures and disease prevalence, known collectively as the exposome-lead to differentiation in the human microbiome and what are the implications of this differentiation for society, politics, and governance? Indeed, the very fact that the environmental microbiome emerged alongside the genome as a key theme for understanding the human microbiome points to an appreciation of the extent to which these areas are mutually constitutive. For example, human microbiomes can hold traces of living conditions (the exposome) which can in turn inform questions of inequality and social (in)justice (Mansfield and Guthman, 2015; Stallins et al., 2018).

A second group of questions spoke more directly to current work in the humanities and social sciences concerned with how the human microbiome is changing conceptions of human singularity (Pradeu, 2012; Rees et al., 2018; Rhodes et al., 2013). Interestingly, such questions did not always arise when and where expected, i.e. under the themes of 'conceptualising' and 'thinking with' microbes, although this may be (as one participant observed) due to the composition of the workshop discussion groups. Discussion of the environment and the microbiome, for example, raised questions about how biological and microbiological histories play into contemporary biological research. Participants noted that much of the Human Microbiome Project has been about natural history, documenting kinds of life and often conforming to a neo-primitivist story of 'this is what the original human microbiome looks like' (Maroney, 2017). Or to put it another way the idea that the gut microbiome of indigenous people probably reflects the original state of the human microbiome, while modern populations have less diverse microbiomes which are 'missing' certain microorganisms. Such assumptions naturalise particular approaches to the human microbiome with consequences for what is understood to be a healthy microbiome, what aspects of the microbiome are seen to merit investment and further research, and how emerging knowledges are put into use (Leiper, 2019; Yong, 2016). A second key area of concern, also noted by Rhodes et al. (2013), was the impact of the human microbiome on questions of citizenship and identity. This point was reflected in concern expressed by participants that microbial data might become another form of bioinformation used to evaluate and classify the legal or health status of certain subsets of the population (M'Charek, 2005).

Continuing with the theme of the microbiome as a bioinformatic resource, a third set of questions examined the ways in which the human microbiome is being valued, commodified and marketed, and considered the extent to which the human microbiome can both conform to, but also perhaps challenge, received understandings of property rights (e.g. intellectual property). This set of research interests resonates strongly with other emerging work around the social science of the microbiome (Chuong et al., 2017; Hawkins and O'Doherty, 2011; Rhodes et al., 2013). A common insight from this line of work is that the microbiome is not an easily extracted and traded fungible unit, but rather a collection of things, or even an ecosystem, which poses challenges to traditional processes of valuation and commodification. Discussions also echoed the ELSI raised around other areas of rapid scientific growth, development and investment, notably the Human Genome Project (Rhodes et al., 2013). Hence questions were posed about the existence and potential exploitation of 'indigenous microbiomes', in a manner not dissimilar to concerns expressed over the exploitation of indigenous DNA and bioprospecting (Armsworth et al., 2010; Parker et al., 2014). Distinctive from Rhodes et al.'s (2013) account, however, was the discussion of the relationship between science, commerce and the production of microbiome knowledges, and in particular the question of whether scientific innovation drives the growth of commercial markets-in probiotics, for example-or vice versa, or even if the two are mutually constitutive. This draws attention to the different (and sometimes competing) understandings of the microbiome produced by scientific research and commercial campaigns, and how these are linked to different value systems.

A fourth related area of concern was how diverse publics engage with the microbiome. Questions included an interest in how publics narrate and visualise the microbiome, if they do so at all. Building on this, a subtheme of 'engaging publics' more explicitly sought to address how such microbial imaginations (Nerlich, 2015; Nerlich and Hellsten, 2009) might shape existing and future engagements with the microbiome, both within and beyond the scope of current scientific research or policy concern. Attention was drawn to the need to understand how particular versions or narratives of the microbiome gain credibility and circulate, with questions raised as to who gains from having or generating credible microbial knowledge (see section above on Commercialisation) and who has the power to access microbial knowledges through particular technologies and techniques (see section below on Research). Similarly, the ways in which the microbiome is narrated also has implications for the formation and generation of particular publics; both those who are interested in the human microbiome as it overlaps with their particular questions or concerns (e.g. links between microbial dysbiosis and autoimmune disease) and who are interesting (e.g. as hosts of novel or potentially valuable microbiomes, such as the indigenous populations noted above). Participants also noted the different modes of public engagement arising around the microbiome, including crowdsourced research and citizen science projects (see, for example, uBiome), a feature that sets these postELSI forms of microbionomic public participation apart from traditional, top-down approaches to human genome research (Balmer et al., 2015; M'Charek, 2005). Such modes of engagement offer a number of potential roles for social scientists, ranging from more familiar interventions, such as facilitating participatory workshops and representing public interests on project advisory and ethical review boards, to the development of novel forms of art-science collaboration (Born and Barry, 2010) to experiment with possible microbial futures or participatory metagenomics (Hodgetts et al., 2018).

In the discussion, concerns arose about whom was given credibility as a microbiome expert, a theme explored through the example of the promissory claims made by both anti- and probiotic cleaning companies. This discussion of expertise raised further questions about the role of social scientists in the process of making the microbiome public. Does social science merely observe and report, or should social scientists also try to arbitrate towards the production of particular kinds of human-microbiome relations? Interestingly, this theme also arose in discussions about 'researching the microbiome,' where participants noted that 'it's important to make sure that, in future research on the microbiome, social scientists are not just observing the scientists, or enrolled by scientists to speak for the social perception of the microbiome'. This led to some discussion about whether social scientists were able to define new modes of public engagement and collaboration, as trialled by the 
recent Good Germs, Bad Germs project (Lorimer et al., 2019) which proved a key source of inspiration and data for this exercise.

Finally, and in some ways linked to the opening discussion of engaging publics and leading on from the points about collaborative and experimental approaches, there was a strand of questioning around methodology. The human microbiome is framed in particular ways, not only through the process of scientific research but also through a whole series of competing knowledge production processes that unfold inside and outside the lab, ranging from established concerns about germs and disease, through to the diverse forms of lay microbiology found in, for example, cheese making (Paxson, 2008). This invited reflections on the need for inter and transdisciplinary expertisesomething which has also been noted by other prominent discussions of emerging microbiome research agendas (Microbiology Society, 2017). This point implies expanding the scope of who should be involved in setting research agendas to include both a wide variety of academic disciplines (as reflected in the constitution of this group), but also lay publics-even if these practices of inclusion pose additional challenges (Hodgetts et al., 2018). Underlying these research questions was a fundamental concern about how to exchange and disseminate knowledge around the human microbiome without re-establishing and cementing traditional lay/expert divides. How do you talk about something as abstract as the microbiome without pre-setting the terms of that discussion? The abstract nature of a concept like the human microbiome raises a set of practical challenges. The scale, complexity and diversity of the microbiome might clash with infrastructures/equipment and techniques of traditional lab science built around specific organisms/species. How is the 'ecological' view of the microbiome translated into new kinds of scientific research methods (Johnson and Burnet, 2016)?

The overall agenda, therefore, reflects conceptual questions, methodological concerns and practical implications for policy and public engagement. As noted above, it both complements and extends existing work and previous agendas, but is distinctive in its attention to questions of context, microbial differentiation, the specific relationships between scientific and commercial interests, expertise and sources of knowledge, and the role of social scientists in making the human microbiome public.

Evaluation of exercise. In this section we draw comparisons with previous agenda-setting exercises and examine the strengths and limitations of our approach to generating a research agenda. At the same time, we draw out some of the complexities and challenges thrown up by positioning the microbiome as an object of social science research.

Initial challenges arose around the microbiome itself as an object of enquiry. We could, for example, take inspiration from the parallels drawn with the ELSI arising in relation to the Human Genome Project (Rhodes et al., 2013). As Balmer et al. (2015) note, the ELSI agenda has played a significant role in opening up new field of enquiry for social scientists enabling them to work in collaboration with scientists and researchers in emerging fields. The ELSI agenda brings with it opportunities, in terms of access and the chance to influence the development of novel technologies, but also can often see social science being positioned as "being responsible for the identification and remediation of potential negative downstream consequences of science' (Balmer et al., 2015, p. 4). Yet the breadth of the questions set out above, which identify the complex interrelations between the microbiome and key social issues such as public health, access to medicines, commercialisation (seen in the ways in which the field is shaped by significant scientific and industrial entrepreneurship), biohacking and identity, suggest a role for both social scientists, and society more broadly (seen in the diverse array of publics detailed in question 26), in shaping the direction, resourcing and scope of microbiome research. Furthermore, both the microbiome and the field of microbiome research are heterogeneous, diverse and rapidly evolving. Here the value of the collective agenda-setting approach for understanding the human microbiome really made itself felt, as the diversity and complexity of the group and their experiences of and understandings of the human microbiome allowed an appreciation of its complexity in a social context. For example, the material composition and location of the human gut microbiome-inside the human body and directly accessible through the act of eating-makes the possibility of DIY microbiome experimentation or biohacking much closer (at least for now) than say DIY hacking of the human genome. So, while those participants working in medicine and allied fields drew attention to the ways in which innovations in medical interventions into the microbiome were moving from bench to bedside, social scientists scoping public engagements with the microbiome drew attention to the potential flow of knowledge, experience and expertise from bedside to bench (question 4).

A second challenge is raised by the nature of our agendasetting exercise itself. It combines a commitment to academic rigour (Rhodes et al., 2013; Sutherland et al., 2011), with a number of key principles, namely inclusivity, openness and democracy. Such commitments are reflected in the open and inclusive way in which we tried to structure this process, the range and diversity of our participants' disciplinary backgrounds, and their willingness to both engage with and challenge each other's perspectives. Nonetheless, bringing together a diverse group of stakeholders also revealed points of tension, where different approaches, languages, understandings and priorities remained hard to reconcile. Questioning the terminology and underlying assumptions associated with different research traditions allows the key issues and concerns to be not only interrogated but expressed in ways which are sensitive to and open to responses from a much more diverse range of research expertise. Furthermore, by framing the exercise as one which had to generate a 'shared social-scientific research agenda' which could 'inform future interdisciplinary scholarship' and bring together researchers from the social sciences, natural sciences, the humanities and non-academic stakeholders, we also established a set of norms which to some extent foreclosed the development of other kinds of research agenda. This exercise would probably have looked very different if we had instead focused on the implications of 'thinking with microbes' for social theory (Hird, 2009).

The emerging nature of much microbiome research (and data) also poses challenges. For example, the group discussing the 'Microbiome and environment' theme noted the ongoing challenge of a lack of basic biogeographical knowledge about the environmental microbiome; its composition, dynamics, drivers and functions. While efforts to map microbial biodiversity continue apace, the challenge of interpreting that data makes it hard to anticipate the implications of microbial biogeography for human health. Furthermore, participants were keen to point out that the microbiome is multiple, since different microbial communities inhabit different bodily sites (e.g. oral microbiome, skin microbiome, gut microbiome) and that it perhaps makes more sense to speak of microbiomes in the plural rather than the singular. This raises questions about how these are delineated for research. Does the human microbiome refer only to microbes on, in and beneath the skin, or does it incorporate those present in the immediate environment, such as houses, farms or factories? Does it make more sense to focus on particular phyla, genera or 
species of microbes (although the species concept is not easily applied to bacteria given the extensive gene transfer between them)? Here we might also note how these questions resonate with similar classificatory problems explored by social scientists working on toxicants and chemicals (Boudia et al., 2018).

This multiplicity of the human microbiome has implications for the scope of this kind of agenda-setting exercise. For Sutherland et al. (2011, p. 244) a key issue was establishing 'precise geographical boundaries' for their agenda. One of the first things we learnt from the human microbiome is not only that such boundaries are difficult if not impossible to establish (there is a constant two-way traffic of microbes into and out of the human), but also that insisting on such boundaries risks creating a flawed and limited understanding of the human microbiome itself. Furthermore, historians and social scientists remind us that the 'human' in the 'human microbiome' is an equally complicated and fluid category (Helmreich, 2015). Does it make sense, for example, to speak of microbes associated with poverty, social marginalisation or unequal access to health resources? How far can we pursue this sort of enquiry before encountering a form of microbiological determinism, and rehearsing older associations between social abjection and pathogenic microbes (Craddock, 2000)? This raises further questions about the current focus of microbiome research and funding calls towards AMR, particularly in the social sciences and humanities. As one participant put it, within the UK context 'It is hard not to route everything through AMR, because that's where the money is, which precludes many things that are most interesting about the microbiome'. Therefore, a key question is how we draw boundaries-rather than the boundaries themselves-and whether we should draw boundaries at all (see theme Conceptualising the microbiome).

\section{Conclusions}

The human microbiome is a rapidly developing area of scientific research and social interest. In common with other emergent areas of science and technology, the social sciences and the humanities can play an important role in exploring aspects of this novel reality, facilitating the development of research that is socially relevant, and incorporating understandings of social and cultural norms and ideas about microbiota into research endeavours. Consequently, a number of research agendas have emerged which offer directions for future social science and humanities research in this area.

An interdisciplinary research agenda requires moving across different fields, and sustaining hybrid modalities of knowledge over time, instituting 'greater openness and transparency about the diversity of ways to understand and address particular problems' (Stirling, 2014). The specific agenda that emerged from our exercise undoubtedly reflects the unique combination of expertise and perspectives brought by the participants. In drawing together diverse stakeholders and academic perspectives, in particular from those working in fields not always explicitly engaging with microbiomes, we have highlighted the importance of attending to the context, intensity, specificity and duration of human-microbe interactions. We have also revealed the significance of the different ways in which commercial and scientific authorities value microbes and communicate information about them, the need for careful reflection on the ways in which publics are engaged with microbiome research and the role of social scientists in shaping such engagements.

Taken collectively, our agenda of 32 questions and their related themes point to eight key priorities for future social science research:
1. To think seriously about the impact of new knowledge about the microbiome on healthcare governance and practice, paying close attention to where such knowledge is produced, by whom and to whose benefit.

2. To examine how 'microbiomania' (Helmreich, 2015) is reshaping human-microbe relations, with implications for public understandings of the relationship between health, hygiene and cleanliness.

3. To collaborate with scholars in the sciences to understand how the human microbiome is situated within a broader environmental microbiome (exposome) and subject to the influence of environmental governance practices in fields such as (One) health, agriculture, sustainability and biosecurity.

4. To collaborate with scholars in the arts and humanities to understand how particular versions, imaginaries or narratives of the microbiome gain credibility and circulate.

5. To consider the impact of microbial knowledges on social practices, including senses of self, identity and citizenship.

6. To consider how the microbe is being valued and commodified, and how this might challenge our ideas of what can be commodified, and how values are assigned and rationalised.

7. To examine the relationship between the microbiome and its publics, including a consideration of how publics and interest groups orientate themselves through particular kinds of relations to the microbiome (as a source of disease or health, as an aspect of the environment to be nurtured or controlled), and to experiment with diverse approaches to engaging publics with the microbiome.

8. To interrogate the relationship between the microbiome and academic research, questioning which epistemologies and ontologies shape microbiome research and considering their implications for future inter and transdisciplinary work.

Our exercise also served to highlight some of the challenges in developing a social-scientific research agenda on the human microbiome. Firstly, the difficulties of identifying who might be considered a stakeholder or relevant public for research on human-microbiome interactions, given that many of the issues and stakeholders have yet to emerge. Secondly, the challenges posed by the materiality of the human microbiome itself as a research object, which is rapidly evolving and in constant interaction and flux with its environment, and which is accessible not only through scientific techniques, but through everyday practices such as cleaning and eating, making it hard to delimit its boundaries, and the boundaries of a research agenda related to it. Our discussion also highlighted what may be lost in seeking to close down or to define too tightly what counts as microbiome research in the first instance, resonating with developments in social science work on AMR which is taking inspiration from (and inspiring) the microbiome research agenda and diversifying its areas of concern to include not only pathogenic microbes.

We therefore anticipate that our agenda will offer guidance and inspiration for both social scientists and funders to broaden their agendas for social science research on the human microbiome, and recognise the ways in which such work can not only service but also shape emerging human-microbiome knowledge.

\section{Data availability}

The data generated through this exercise are presented in full in the Results section (Table 1).

Received: 19 July 2019; Accepted: 23 December 2019; Published online: 31 January 2020 


\section{References}

Armsworth PR, Armsworth AN, Compton N, Cottle P, Davies I, Emmett BA, Fandrich V, Foote M, Gaston KJ, Gardiner P, Hess T, Hopkins J, Horsley N, Leaver N, Maynard T, Shannon D (2010) The ecological research needs of business. J Appl Ecol 47:235-243. https://doi.org/10.1111/j.13652664.2010.01792.x

Balmer AS, Calvert J, Marris C, Molyneux S, Frow E, Kearnes M, Bulpin K, Schyfter P, Mackenzie A, Martin P (2015) Taking roles in interdisciplinary collaborations: reflections on working in post-ELSI spaces in the UK synthetic biology community. Sci Technol Stud 28:3-25

Balmer AS, Calvert J, Marris C, Molyneux-Hodgson S, Frow E, Kearnes M, Bulpin K, Schyfter P, Mackenzie A, Martin P (2016) Five rules of thumb for postELSI interdisciplinary collaborations. J Responsible Innov 3:73-80. https:// doi.org/10.1080/23299460.2016.1177867

Barry A, Born G, Weszkalnys G (2008) Logics of interdisciplinarity. Econ Soc 37:20-49. https://doi.org/10.1080/03085140701760841

Benezra, A (2016) Datafying microbes: Malnutrition at the intersection of genomics and global health. BioSocieties 11(3): 334-351

Benezra, A (2018) Making microbiomes. In: Gibbon S, Prainsack B, Hilgartner S, Lamoreaux J (eds) Routledge Handbook of Genomics, Health, and Society, Routledge, New York

Benezra A, DeStefano J, Gordon JI (2012) Anthropology of microbes. Proc Natl Acad Sci USA 109:6378-6381. https://doi.org/10.1073/pnas.1200515109

Blaser MJ (2014) Missing microbes: how killing bacteria creates modern plagues. Oneworld Publications

Bloomfield S (2016) In future we are going to have to view our microbial world very differently. Perspect Public Health 136:183-185. https://doi.org/10.1177/ 1757913916650336

Born G, Barry A (2010) ART-SCIENCE: from public understanding to public experiment. J Cult Econ 3:103-119. https://doi.org/10.1080/17530351003617610

Boudia S, Creager ANH, Frickel S, Henry E, Jas N, Reinhardt C, Roberts JA (2018) Residues: rethinking chemical environments. Engag Sci Technol Soc 4:165-178. https://doi.org/10.17351/ests2018.245

Brown RR, Deletic A, Wong THF (2015) Interdisciplinarity: how to catalyse collaboration. Nature 525:315-317. https://doi.org/10.1038/525315a

Callard F, Fitzgerald D (n.d.) Rethinking interdisciplinarity across the social sciences and neurosciences. Palgrave Macmillan

Chuong KH, Hwang DM, Tullis DE, Waters VJ, Yau YCW, Guttman DS, O'Doherty KC (2017) Navigating social and ethical challenges of biobanking for human microbiome research. BMC Med. Ethics 18. https://doi.org/ 10.1186/s12910-016-0160-y

Clinch M, Shaw S, Ashcroft R, Swinglehurst D (2018) Liminality in practice: a case study in life sciences research. BioSocieties. https://doi.org/10.1057/s41292018-0128-x

Craddock S (2000) City of plagues: disease, poverty, and deviance in San Francisco. University of Minnesota Press

Crane JT (2011) Viral cartographies: mapping the molecular politics of global HIV. BioSocieties 6:142-166. https://doi.org/10.1057/biosoc.2010.37

Davies GF, Greenhough BJ, Hobson-West P, Kirk RGW, Applebee K, Bellingan LC, Berdoy M, Buller H, Cassaday HJ, Davies K, Diefenbacher D, Druglitrø T, Escobar MP, Friese C, Herrmann K, Hinterberger A, Jarrett WJ, Jayne K, Johnson AM, Johnson ER, Konold T, Leach MC, Leonelli S, Lewis DI, Lilley EJ, Longridge ER, McLeod CM, Miele M, Nelson NC, Ormandy EH, Pallett H, Poort L, Pound P, Ramsden E, Roe E, Scalway H, Schrader A, Scotton CJ, Scudamore CL, Smith JA, Whitfield L, Wolfensohn S (2016) Developing a collaborative agenda for humanities and social scientific research on laboratory animal science and welfare. PLoS ONE 11:e0158791. https://doi. org/10.1371/journal.pone.0158791

Eisen JA (n.d.) Microbiomania. Tree Life. https://phylogenomics.blogspot.com/p/ blog-page.html. Accessed 26 Sep 2019

ESRC (Economic and Social Research Council) (2014) Transformative Research Call

Fiske A, Prainsack B, Buyx A (2019) Meeting the needs of underserved populations: setting the agenda for more inclusive citizen science of medicine. J Med Ethics 45:617-622. https://doi.org/10.1136/medethics-2018-105253

Gilbert JA, Blaser MJ, Caporaso JG, Jansson JK, Lynch SV, Knight R (2018) Current understanding of the human microbiome. Nat Med 24:392-400. https://doi.org/10.1038/nm.4517

Giraldo Herrera CE (2018) Microbes and other shamanic beings. Palgrave Macmillan

Greenhough B, Dwyer A, Grenyer R, Hodgetts T, McLeod C, Lorimer J (2018) Unsettling antibiosis: how might interdisciplinary researchers generate a feeling for the microbiome and to what effect? Palgrave Commun 4:149. https://doi.org/10.1057/s41599-018-0196-3

Hawkins AK, O’Doherty KC (2011) “Who owns your poop?": Insights regarding the intersection of human microbiome research and the ELSI aspects of biobanking and related studies. BMC Med Genomics 4:72. https://doi.org/ $10.1186 / 1755-8794-4-72$
Helmreich S (2015) Sounding the limits of life: essays in the anthropology of biology and beyond. Princeton University Press, Princeton, New Jersey

Hinchliffe S, Allen J, Lavau S, Bingham N, Carter S (2013) Biosecurity and the topologies of infected life: from borderlines to borderlands. Trans Inst $\mathrm{Br}$ Geogr 38:531-543

Hird MJ (2009) The origins of sociable life: evolution after science studies. Palgrave Macmillan, Basingstoke

Hodgetts T, Grenyer R, Greenhough B, McLeod C, Dwyer A, Lorimer J (2018) The microbiome and its publics. EMBO Rep. 19:e45786. https://doi.org/10.15252/ embr.201845786

Hooper LV, Gordon JI (2001) Commensal host-bacterial relationships in the gut. Science 292:1115-1118

Human Microbiome Project Consortium (2012) A framework for human microbiome research. Nature 486:215-221. https://doi.org/10.1038/nature11209

Johnson KV-A, Burnet PWJ (2016) Microbiome: should we diversify from diversity? Gut Microbes 7:455-458. https://doi.org/10.1080/19490976.2016. 1241933

Krzywoszynska A (2019) Caring for soil life in the Anthropocene: the role of attentiveness in more-than-human ethics. Trans Inst Br Geogr 44:661-675. https://doi.org/10.1111/tran.12293

Landecker H (2016) Antibiotic resistance and the biology of history. Body Soc 22:19-52

Latour B (2004) Why has critique run out of steam? From matters of fact to matters of concern. Crit Inq 30:225-248

Lederberg J (2004) Of men and microbes. New Perspect. 21:92-96

Leiper C (2019) The paleo paradox: re-wilding as a health strategy across scales in the anthropocene. Geoforum 105:122-130

Lorimer J (2017) Parasites, ghosts and mutualists: a relational geography of microbes for global health. Trans Inst Br Geogr 42:544-558. https://doi.org/ 10.1111/tran.12189

Lorimer J (2016) Gut buddies multispecies studies and the microbiome. Environ Humanities 8:57-76. https://doi.org/10.1215/22011919-3527722

Lorimer J, Hodgetts T, Grenyer R, Greenhough B, McLeod C, Dwyer A (2019) Making the microbiome public: participatory experiments with DNA sequencing in domestic kitchens. Trans Inst Br Geogr 44:524-541

Mansfield B, Guthman J (2015) Epigenetic life: biological plasticity, abnormality, and new configurations of race and reproduction. Cult Geogr 22:3-20

Maroney S (2017) Reviving colonial science in ancestral microbiome research. MicrobioSocial. https://microbiosocial.wordpress.com/2017/01/10/revivingcolonial-science-in-ancestral-microbiome-research/. Accessed 3 Apr 2019

McFarland LV (2015) From yaks to yogurt: the history, development, and current use of probiotics. Clin Infect Dis Publ Infect Dis Soc Am 60(Suppl 2): S85-S90. https://doi.org/10.1093/cid/civ054

M'Charek A (2005) The human genome diversity project: an ethnography of scientific practice. Cambridge University Press, Cambridge

Metchnikoff E (2016) The prolongation of life: optimistic studies. Springer Publishing Company

Metchnikoff E (1903) Les microbes intestinaux. Bull Inst Pasteur 1:217-225. 265-282

Microbiology Society (2017) Unlocking the microbiome: opportunities and challenges of microbiome research for health, agriculture, environment and biotechnology. Microbiology Society, London. https://microbiologysociety. org/our-work/the-microbiome/unlocking-the-microbiome-report.html

Nading A (2016) Evidentiary symbiosis: on paraethnography in human-microbe relations. Sci Cult 25:560-581. https://doi.org/10.1080/09505431.2016.1202226

National Academies of Sciences Engineering Medicine (2017) Microbiomes of the built environment: a research agenda for indoor microbiology, human health, and buildings. https://doi.org/10.17226/23647

National Academies of Sciences, Engineering and Medicine (2007) The new science of metagenomics: revealing the secrets of our microbial planet. The National Academies Press

Neiderhuber M (2015) The human microbiome and media confusion. Science News. http://sitn.hms.harvard.edu/flash/2015/the-human-microbiome-andmedia-confusion/. Accessed 2 Apr 2019

Nerlich B (2015) Genes, microbes, us [WWW Document]. Mak. Sci. Public. http:// blogs.nottingham.ac.uk/makingsciencepublic/2015/03/16/genes-microbes-us/. Accessed 3 Apr 2019

Nerlich B, Hellsten I (2009) Beyond the human genome: microbes, metaphors and what it means to be human in an interconnected post-genomic world. $\mathrm{N}$. Genet Soc 28:19-36. https://doi.org/10.1080/14636770802670233

Nowotny H (2016) Investigating interdisciplinary collaboration: theory and practice across disciplines. Rutgers University Press, New Brunswick, New Jersey

O’Neill J (2014) Antimicrobial resistance: tackling a crisis for the health and wealth of nations. http://www.jpiamr.eu/wp-content/uploads/2014/12/AMR-ReviewPaper-Tackling-a-crisis-for-the-health-and-wealth-of-nations_1-2.pdf

Parker M, Acland A, Armstrong HJ, Bellingham JR, Bland J, Bodmer HC, Burall S, Castell S, Chilvers J, Cleevely DD, Cope D, Costanzo L, Dolan JA, Doubleday R, Feng WY, Godfray HCJ, Good DA, Grant J, Green N, Groen AJ, Guilliams 
TT, Gupta S, Hall AC, Heathfield A, Hotopp U, Kass G, Leeder T, Lickorish FA, Lueshi LM, Magee C, Mata T, McBride T, McCarthy N, Mercer A, Neilson R, Ouchikh J, Oughton EJ, Oxenham D, Pallett H, Palmer J, Patmore J, Petts J, Pinkerton J, Ploszek R, Pratt A, Rocks SA, Stansfield N, Surkovic E, Tyler CP, Watkinson AR, Wentworth J, Willis R, Wollner PKA, Worts K, Sutherland WJ (2014) Identifying the science and technology dimensions of emerging public policy issues through horizon scanning. PLoS ONE 9: e96480. https://doi.org/10.1371/journal.pone.0096480

Paxson H (2008) Post-Pasteurian cultures: the microbiopolitics of raw-milk cheese in the United States. Cult Anthropol 23:15-47

Paxson H, Helmreich S (2014) The perils and promises of microbial abundance: novel natures and model ecosystems, from artisanal cheese to alien seas. Soc Stud Sci 44:165-193. https://doi.org/10.1177/0306312713505003

Pradeu T (2012) The limits of the self: immunology and biological identity. Oxford University Press

Rees T, Bosch T, Douglas AE (2018) How the microbiome challenges our concept of self. PLOS Biol 16:e2005358

Rhodes R, Gilgorov N, Schwab A (2013) The human microbiome: ethical, legal and social concerns. Oxford University Press, Oxford

Roberts DE (2012) Fatal interventions: how science, politics, and big business recreate race in the twenty-first century. The New Press, New York, NY

Royal Society for Public Health (2019) Too clean or not too clean: the case for targeted hygiene in the home and everyday life. Royal Society for Public Health, London. https://www.rsph.org.uk/uploads/assets/uploaded/06b37f302241-4e98-aba93fc15346e7a5.pdf

Sangodeyi FI (2014) The making of the microbial body, 1900s-2012. Doctoral dissertation. Harvard University

Shamarina D, Stoyantcheva I, Mason CE, Bibby K, Elhaik E (2017) Communicating the promise, risks, and ethics of large-scale, open space microbiome and metagenome research. Microbiome 5:132. https://doi.org/10.1186/ s40168-017-0349-4

Shnayerson M, Plotkin M (2002) The killers within: the deadly rise of drugresistant bacteria. Little, Brown \& Company, London

Stallins JA, Law DM, Strosberg SA, Rossi JJ (2018) Geography and postgenomics: how space and place are the new DNA. GeoJournal 83:153-168

Stilgoe J, Owen R, Macnaghten P (2013) Developing a framework for responsible innovation. Res Policy 42:1568-1580. https://doi.org/10.1016/j. respol.2013.05.008

Stirling A (2014) Disciplinary dilemma: working across research silos is harder than it looks. The Guardian

Sutherland WJ, Adams WM, Aronson RB, Aveling R, Blackburn TM, Broad S, Ceballos G, Côté IM, Cowling RM, Da Fonseca GaB, Dinerstein E, Ferraro PJ, Fleishman E, Gascon C, Hunter M, Hutton J, Kareiva P, Kuria A, Macdonald DW, Mackinnon K, Madgwick FJ, Mascia MB, McNeely J, Milner-Gulland EJ, Moon S, Morley CG, Nelson S, Osborn D, Pai M, Parsons ECM, Peck LS, Possingham H, Prior SV, Pullin AS, Rands MRW, Ranganathan J, Redford KH, Rodriguez JP, Seymour F, Sobel J, Sodhi NS, Stott A, Vance-Borland K, Watkinson AR (2009) One hundred questions of importance to the conservation of global biological diversity. Conserv Biol J Soc Conserv Biol 23:557-567. https://doi.org/10.1111/j.1523-1739.2009.01212.x

Sutherland WJ, Armstrong-Brown S, Armsworth PR, Tom B, Brickland J, Campbell CD, Chamberlain DE, Cooke AI, Dulvy NK, Dusic NR, Fitton M, Freckleton RP, Godfray HCJ, Grout N, Harvey HJ, Hedley C, Hopkins JJ, Kift NB, Kirby J, Kunin WE, Macdonald DW, Marker B, Naura M, Neale AR, Oliver T, Osborn D, Pullin AS, Shardlow MEA, Showler DA, Smith PL, Smithers RJ, Solandt J-L, Spencer J, Spray CJ, Thomas CD, Thompson J, Webb SE, Yalden DW, Watkinson AR (2006) The identification of 100 ecological questions of high policy relevance in the UK. J Appl Ecol 43:617-627. https://doi.org/10.1111/j.1365-2664.2006.01188.x

Sutherland WJ, Bellingan L, Bellingham JR, Blackstock JJ, Bloomfield RM, Bravo M, Cadman VM, Cleevely DD, Clements A, Cohen AS, Cope DR, Daemmrich AA, Devecchi C, Anadon LD, Denegri S, Doubleday R, Dusic NR, Evans RJ, Feng WY, Godfray HCJ, Harris P, Hartley SE, Hester AJ, Holmes J, Hughes A, Hulme M, Irwin C, Jennings RC, Kass GS, Littlejohns P, Marteau TM, McKee G, Millstone EP, Nuttall WJ, Owens S, Parker MM, Pearson S, Petts J, Ploszek R, Pullin AS, Reid G, Richards KS, Robinson JG, Shaxson L, Sierra L, Smith BG, Spiegelhalter DJ, Stilgoe J, Stirling A, Tyler CP, Winickoff
DE, Zimmern RL (2012) A collaboratively-derived science-policy research agenda. PLoS ONE 7:e31824. https://doi.org/10.1371/journal.pone.0031824

Sutherland WJ, Fleishman E, Mascia MB, Pretty J, Rudd MA (2011) Methods for collaboratively identifying research priorities and emerging issues in science and policy. Methods Ecol Evol 2:238-247. https://doi.org/10.1111/j.2041210X.2010.00083.x

Tackling AntiMicrobial Resistance (AMR) - Arts and Humanities Research Council (n.d.) [WWW Document]. https://ahrc.ukri.org/research/fundedthemesandprogrammes/ crosscouncilprogrammes/amr/. Accessed 3 Apr 2019

The Integrative Human Microbiome Project (2019) Nature 569, 641. https://doi. org/10.1038/s41586-019-1238-8

Time for the social sciences (2015) Nat. News 517, 5. https://doi.org/10.1038/ 517005a

UBiome (n.d.) Microbiome testing. Microbiome Test. https://ubiome.com. Accessed 10 Oct 2019

Velasquez-Manoff M (2012) An epidemic of absence: a new way of understanding allergies and autoimmune diseases. Scribner

Wolf-Meyer MJ (2017) Normal, regular, and standard: scaling the body through fecal microbial transplants. Med Anthropol Q 31:297-314. https://doi.org/ $10.1111 /$ maq. 12328

Yong E (2016) I contain multitudes: the microbes within us and a grander view of life. Penguin Random House, London

\section{Acknowledgements}

This project was organised and funded as part of the Oxford Interdisciplinary Microbiome Project (IMP) and supported by the John Fell Fund and the Economic and Social Research Council grant number ES/N006968/1.

\section{Author contributions}

The production of the paper was led by Greenhough, with major input from other Oxford IMP members, Jervis-Read, Lezaun, Lorimer and McLeod. All invited participants who contributed to the generation, reflection and refining of the final prioritised list of 32 questions were also invited to be co-authors of the paper and those who accepted this invitation played a significant role in revising and editing the manuscript (see author list)

\section{Competing interests}

The authors declare no competing interests.

\section{Additional information}

Correspondence and requests for materials should be addressed to B.G.

Reprints and permission information is available at http://www.nature.com/reprints

Publisher's note Springer Nature remains neutral with regard to jurisdictional claims in published maps and institutional affiliations.

Open Access This article is licensed under a Creative Commons Attribution 4.0 International License, which permits use, sharing, adaptation, distribution and reproduction in any medium or format, as long as you give appropriate credit to the original author(s) and the source, provide a link to the Creative Commons license, and indicate if changes were made. The images or other third party material in this article are included in the article's Creative Commons license, unless indicated otherwise in a credit line to the material. If material is not included in the article's Creative Commons license and your intended use is not permitted by statutory regulation or exceeds the permitted use, you will need to obtain permission directly from the copyright holder. To view a copy of this license, visit http://creativecommons.org/ licenses/by/4.0/

(C) The Author(s) 2020 
Beth Greenhough (10 ${ }^{1 \star}$, Cressida Jervis Read (10 1, Jamie Lorimer ${ }^{1}$, Javier Lezaun (1) ${ }^{1}$, Carmen McLeod ${ }^{2,3}$,

Amber Benezra (10 ${ }^{4}$, Sally Bloomfield ${ }^{5}$, Tim Brown (10 ${ }^{6}$, Megan Clinch ${ }^{6}$, Fulvio D'Acquisto ${ }^{7}$, Anna Dumitriu ${ }^{8}$, Joshua Evans ${ }^{1}$, Nicola Fawcett ${ }^{1}$, Nicolas Fortané ${ }^{9}$, Lindsay J. Hall $\mathbb{B}^{10}$, César E. Giraldo Herrera ${ }^{11}$, Timothy Hodgetts ${ }^{1}$, Katerina Vicky-Ann Johnson ${ }^{1}$, Claas Kirchhelle (iD) ${ }^{1}$, Anna Krzywoszynska (i) ${ }^{12}$, Helen Lambert ${ }^{13}$, Tanya Monaghan ${ }^{2}$, Alex Nading (14 ${ }^{14}$, Brigitte Nerlich (1) ${ }^{2}$, Andrew C. Singer (15), Erika Szymanski (1) ${ }^{16} \&$ Jane Wills ${ }^{17}$

${ }^{1}$ University of Oxford, Oxford, UK. ${ }^{2}$ University of Nottingham, Nottingham, UK. ${ }^{3}$ Newcastle University, Newcastle upon Tyne, UK. ${ }^{4}$ Stevens Institute of Technology, Hoboken, USA. ${ }^{5}$ London School of Hygiene and Tropical Medicine, London, UK. ${ }^{6}$ Queen Mary University of London, London, UK. ${ }^{7}$ University of Roehampton, Roehampton, UK. ${ }^{8}$ Brighton and Sussex Medical School, Brighton, UK. ${ }^{9}$ INRA, Paris-Dauphine University, Paris, France.

${ }^{10}$ Quadram Institute Bioscience, Norwich, UK. ${ }^{11}$ Leibniz-Centre for Tropical Marine Research, Bremen, Germany. ${ }^{12}$ University of Sheffield,

Sheffield, UK. ${ }^{13}$ University of Bristol, Bristol, UK. ${ }^{14}$ Brown University, Providence, USA. ${ }^{15}$ UK Centre for Ecology \& Hydrology, Wallingford, UK.

${ }^{16}$ Colorado State University, Fort Collins, USA. ${ }^{17}$ University of Exeter, Exeter, UK. *email: beth.greenhough@ouce.ox.ac.uk 